\title{
Global experience with an inner branched arch endograft
}

\author{
Stéphan Haulon, MD, PhD, ${ }^{a}$ Roy K. Greenberg, MD, ${ }^{b}$ Rafaëlle Spear, MD, ${ }^{a}$ Matt Eagleton, MD, \\ Cherrie Abraham, MD ${ }^{\mathrm{c}}$ Christos Lioupis, MD, ${ }^{\mathrm{c}}$ Eric Verhoeven, MD, PhD,${ }^{\mathrm{d}}$ Krassi Ivancev, MD, \\ Tilo Kölbel, MD, PhD, ${ }^{\mathrm{f}}$ Brendan Stanley, MD, ${ }^{\mathrm{g}}$ Timothy Resch, MD, ${ }^{\mathrm{h}}$ Pascal Desgranges, MD, PhD, \\ Blandine Maurel, MD, ${ }^{\mathrm{a}}$ Blayne Roeder, $\mathrm{PhD},{ }^{\mathrm{j}}$ Timothy Chuter, $\mathrm{MD},{ }^{\mathrm{k}}$ and Tara Mastracci, $\mathrm{MD}^{\mathrm{b}}$
}

Background: Branched endografts are a new option to treat arch aneurysm in high-risk patients.

Methods and results: We performed a retrospective multicenter analysis of all patients with arch aneurysms treated with a new branched endograft designed with 2 inner branches to perfuse the supra aortic trunks. Thirty-eight patients were included. The median age was 71 years (range, 64-74 years). An American Society of Anesthesiologists score of 3 or 4 was reported in $89.5 \%$ (95\% confidence interval [CI], 79.7-99.3) of patients. The 30-day mortality rate was $13.2 \%$ (95\% CI, 2.2-24.2). Technical success was obtained in 32 patients $(84.2 \%$ [95\% CI, 72.4-95.9]). Early secondary procedures were performed in 4 patients (10.5\% [95\% CI, 0.7-20.3]). Early cerebrovascular complications were diagnosed in 6 patients $(15.8 \%$ [95\% CI, 4.0-27.6]), including 4 transient ischemic attacks, 1 stroke, and 1 subarachnoid hemorrhage. The median follow-up was 12 months (range, 6-12 months). During follow-up, no aneurysm-related death was detected. Secondary procedures during follow-up were performed in 3 patients $(9.1 \%$ [95\% CI, 0.0-19.1]), including 1 conversion to open surgery. We compared the first 10 patients (early experience group) with the subsequent 28 patients. Intraoperative complications and secondary procedures were significantly higher in the early experience group. Although not statistically significant, the early mortality was higher in the early experience group $(30 \%$ [ $95 \%$ CI, 0.0-60.0]) versus the remainder (7.1\% [95\% CI, 0.0-16.9]; $P=.066)$. Being part of the early experience group and ascending aortic diameter $\geq 38 \mathrm{~mm}$ were found to be associated to higher rates of combined early mortality and neurologic complications.

Conclusions: Our preliminary study confirms the feasibility and safety of the endovascular repair of arch aneurysms in selected patients who may not have other conventional options. Clinical trial registration information: Thoracic IDE NCT00583817, FDA IDE\# 000101. (J Thorac Cardiovasc Surg 2014;148:1709-16)

Surgical repair of aneurysms involving the aortic arch is technically challenging. Historically, these aneurysms have been treated with surgical techniques requiring

\footnotetext{
From the Aortic Centre, Hôpital Cardiologique, ${ }^{a}$ Centre Hospitalier Régional Universitaire de Lille, Lille, France; Vascular Surgery, ${ }^{\mathrm{b}}$ Cleveland Clinic Foundation, Cleveland, Ohio; Vascular Surgery, ${ }^{\mathrm{c}}$ Jewish General Hospital, McGill University, Montreal, Quebec, Canada; Vascular and Endovascular Surgery, ${ }^{\mathrm{d}}$ Klinikum Nürnberg Süd, Nürnberg, Germany; Vascular Surgery, ${ }^{\text {e }}$ Royal Free Hospital, London, England; Vascular Medecine, ${ }^{\mathrm{f}}$ University Hospital Eppendorf, Hamburg, Germany; Vascular Surgery, ${ }^{\mathrm{g}}$ Fremantle Hospital, Perth, Australia; Vascular Center, ${ }^{\text {h }}$ Skane University Hospital, Malmö, Sweden; Vascular Center, ${ }^{1}$ Centre Hospitalier Universitaire Mondor, Créteil, France; Cook Medical, ${ }^{\mathrm{j}}$ Bloomington, Ind; and Vascular Surgery, ${ }^{\mathrm{k}}$ Univeristy of California, San Francisco, San Francisco, Calif.

Disclosures: S.H., R.K.G., M.E., C.A., C.L., E.V., K.I., T.K., B.S., T.R., B.R., T.C., and T.M. received consulting, proctoring, research, and travel grants from Cook Medical, Bloomington, Ind. S.H., R.K.G., K.I., T.K., T.R., and T.C. have intellectual property rights with Cook Medical. B.R. is a Cook Medical employee. All other authors have nothing to disclose with regard to commercial support.

Received for publication Jan 2, 2014; revisions received Feb 17, 2014; accepted for publication Feb 20, 2014; available ahead of print March 28, 2014

Address for reprints: Stéphan Haulon, MD, PhD, Chirurgie Vasculaire, CHRU de Lille, INSERM U1008, Université Lille Nord de France, 59037 Lille Cedex, France (E-mail: stephan.haulon@chru-lille.fr).

$0022-5223 / \$ 36.00$

Copyright (c) 2014 by The American Association for Thoracic Surgery

http://dx.doi.org/10.1016/j.jtcvs.2014.02.072
}

cardiopulmonary bypass and deep hypothermic circulatory arrest with a mortality rate ranging from $2 \%$ to $16.5 \%$ and a stroke rate ranging from $2 \%$ to $18 \%{ }^{1,2}$ Hybrid arch repair combines a procedure to secure a proximal landing zone with concomitant endovascular endograft placement in the aortic arch. Although this technique is considered minimally invasive, because it avoids aortic crossclamping and hypothermic circulatory arrest, the morbidity and mortality remains high, with a mortality rate ranging from $0 \%$ to $15 \%$ and a stroke rate from $0 \%$ to $11 \% .^{3}$ Continued development and evolution of endografts has allowed for the application of total endovascular repair of complex aortic aneurysms involving the visceral segment with fenestrated and branched endografts. ${ }^{4-6}$ Good initial results with this later generation of endografts have broadened its use to the aortic arch in high-risk patients. ${ }^{7-9}$

Here we present the multicenter evaluation of the endovascular exclusion of arch aneurysms with branched endografts designed with 2 inner branches to perfuse the supra-aortic trunks. We report our initial experience of all patients treated with this device during the study period, which includes the learning curve in patient selection and implantation at all centers. 


\section{Abbreviations and Acronyms \\ ASA $=$ American Society of Anesthesiologists \\ CTA $=$ computed tomography angiography \\ $\mathrm{EE}=$ early experience \\ LCC $=$ left common carotid \\ $\mathrm{LE}=$ late experience \\ LSA $=$ left subclavian artery \\ $\mathrm{LVEF}=$ left ventricular ejection fraction}

\section{METHODS}

Ten centers participated in this retrospective study (Table 1), which was approved by and met the necessary specifications of the investigational review board at each center. Informed consent was obtained from all patients. Physicians initiated this study under an investigational device exemption protocol in the United States.

From September 2009 to May 2013, all patients who presented with aortic arch dilation deemed unfit for surgery and with an appropriate anatomy for a double inner-branched custom-made endograft treatment were enrolled. Multidisciplinary teams, including cardiovascular surgeons, were involved in the decision making at all centers. Indication for treatment was aortic diameter $>55 \mathrm{~mm}$ or rapid growth $(>10 \mathrm{~mm}$ during the past 12 months). The physicians involved with the initial experience agreed on the following inclusion criteria.

\section{Anatomic Criteria}

Anatomic criteria included arch aneurysms and chronic dissections, no prior aortic valve replacement (biological or mechanical valves), ascending aortic length $\geq 50 \mathrm{~mm}$ (measured from sinotubular junction to origin of innominate artery), sealing zone within the ascending aorta $\geq 40 \mathrm{~mm}$ length and $\leq 38 \mathrm{~mm}$ diameter, innominate artery $\leq 20 \mathrm{~mm}$ in diameter and $\geq 20 \mathrm{~mm}$ in sealing zone length, and iliac access able to accommodate $22 \mathrm{~F}$ or $24 \mathrm{~F}$ sheaths (conduits should be staged).

\section{Physiologic Criteria}

Physiologic criteria included a minimum of 2-year life expectancy, negative stress test (in the setting a positive stress test cardiology clearance required), no class III or IV congestive heart failure, no stroke or myocardial infarction within the past year, no significant carotid bifurcation disease $\geq 75 \%$ stenosis by North American Symptomatic Carotid Endarterectomy Trial criteria, and estimated glomerular filtration rate by modification of diet in renal disease method $\geq 45 \mathrm{~mL} / \mathrm{min} / 1.73 \mathrm{~m}^{2}$.

All patients received anatomic computed tomography angiography (CTA) and physiologic evaluation before treatment. Not all patients in our study met the recommended selection criteria, and in those patients, exceptions were made at the discretion of the treating surgeon. These exceptions were physiologic: renal insufficiency (estimated glomerular filtration rate $<45 \mathrm{~mL} / \mathrm{min}$ ) in 4 cases (associated with LVEF $<40 \%$ in 2 cases and with home oxygen in 1 case), LVFE $<40 \%$ alone in 1 case, and mechanical aortic valve and LVFE $<40 \%$ in 1 case. In addition, 11 patients had an aortic ascending aorta $\geq 38 \mathrm{~mm}$.

\section{Device}

Patients were treated with a branched endograft manufactured by Cook Medical (Bloomington, Ind) designed to adapt to each patient's anatomy (Figure 1). Graft designs were agreed upon by at least 2 investigators at different sites. There are 2 internal side branches (Figure 2, A) with an enlarged external opening at their distal ends (Figure 2, B). Markers are placed on both ends of each inner side branch to facilitate positioning under fluoroscopy. The ends of the endograft are wide and flexible, whereas the middle-the side branch bearing portion-is narrow and straight (Figure 2, C). The design objective was to separate the orifices of the side branches from the orifices of the supra-aortic trunks, preserving perigraft flow and facilitating branch cannulation. The device is loaded into a curved introducer (Figure 3), with a hydrophilic sheath. The curved system facilitates alignment of the branches with the greater curve of the aortic arch. The bridging component for the innominate artery is manufactured with low-profile graft fabric and loaded into a short $14 \mathrm{~F}$ Flexor delivery system (Cook Medical). A commercially available covered stent Fluency (CR Bard, Murray Hill, NJ) or Viabahn (WL Gore, Flagstaff, Ariz) was used as the bridging component for the left common carotid (LCC) artery.

\section{Procedure}

A left subclavian artery (LSA) revascularization is performed before the arch endovascular repair in a 1-step or 2-step procedure (preferred option). To deliver the components, 3 arterial accesses are needed. First, femoral access to insert the endograft over a stiff wire positioned through the aortic valve into to the left ventricle. Second, right common carotid or right axillary access to catheterize the innominate internal side branch and to insert the covered stent bridging the side branch to the innominate trunk. Finally, left axillary access to catheterize the LCC through the LSA transposition or bypass, and the LCC internal side branch to deliver the covered stent bridging the side branch to the LCC.

After systemic heparinization with 100 international units $/ \mathrm{kg}$ (target activated clotting time $>300$ seconds), catheters and/or sheaths are placed to mark the origins of the innominate artery and LCC or LSA, a pigtail catheter is positioned into the apex of the left ventricle from the femoral access, and a stiff wire (Lunderquist; Cook Medical) is advanced through this catheter. The position of the tip of the stiff wire is constantly visualized. Under fluoroscopy, the orientation of the main body of the graft is verified outside the patient and then delivered over the stiff wire to the aortic arch. The tapered short tip is brought through the aortic valve into the left ventricle. An angiogram is performed, the branches along with their associated markers are positioned adequately, and the graft is deployed under rapid pacing (or other cardiac output suppression technique). Normal cardiac output is resumed before withdrawing the tapered tip of the delivery system and the stiff wire from the left ventricle. The side branches are catheterized from the target vessels and sheaths are positioned into the inner side branches. Appropriate bridging limbs and covered stents are advanced through the access sheaths into the target vessels and deployed. On-table angiography is conducted to confirm complete exclusion of the aneurysm and patency of the branches.

\section{Data Collection}

Each center collected demographics, medical history, American Society of Anesthesiologists (ASA) score, aortic arch dilation etiology, proximal landing zone diameter and length, device information, procedure specifics, length of hospitalization, and intraoperative and postoperative events for their patients.

Early events were defined as events occurring within the first 30 postoperative days and late events as events occurring after. Overall mortality included both early mortality and mortality during follow-up.

Data was pooled in an anonymous database housed in a secure location at 1 institution. Planned follow-up included clinical examination and CTA scan evaluation postoperatively, at 6 months, at 12 months, and yearly thereafter.

Technical success, clinical success, and intraoperative and postoperative morbidity and mortality were reported in accordance with the reporting standards. ${ }^{10}$ 
TABLE 1. Trial centers

\section{Center}

No. of patients

Hôpital Cardiologique, CHRU, Lille, France

Cleveland Clinic Foundation, Cleveland, Ohio

10

8

Jewish General Hospital, McGill University,

Montreal, Canada

Royal Free Hospital, London, England

Klinikum Nürnberg Süd, Nürnberg, Germany

Fremantle Hospital, Perth, Australia

University Hospital Eppendorf, Hamburg, Germany

University of California, San Francisco,

San Francisco, Calif

Vascular Center, Skane University Hospital,

Malmö, Sweden

CHU Mondor, Créteil, France

CHRU, Centre Hospitalier Régional Universitaire; $\mathrm{CHU}$, Centre Hospitalier Universitaire.

The lessons learned during the initial first 10 cases were shared by all physicians involved, both by conference calls and by attending surgical procedures performed by others. We thus considered this early experience (EE) group of 10 patients as the initial learning curve in patient selection and device implantation. We compared the results from this EE group with the 28 subsequent patients (the late experience [LE] group).

Risk factors for combined early mortality, strokes, and transient ischemic accident (major adverse events [MAEs]) were investigated.

\section{Statistical Analyses}

Continuous variables are expressed as median with interquartile range, or mean \pm standard deviation. Categorical variable are presented with percentage and 95\% confidence interval (CI). Comparisons between categorical variables were performed with $\chi^{2}$ test, or with Fisher exact test when $<5$ events were observed. When normality was not assessed or when groups were defined with $<30$ patients, comparisons between continuous variables were performed with the Student $t$ test or the Mann-Whitney $U$ test. Statistical analyses were performed using SPSS software (SPSS-IBM Statistics Inc, Armonk, NY).

\section{RESULTS \\ Population Characteristics}

Thirty-eight patients were treated with a double inner side branch aortic arch endograft. None of the patients treated had any evidence of connective tissue disorders. An ASA score of 3 or 4 was reported for 34 patients (89.5\% [95\% CI, 79.7-99.3]). The characteristics of the population are presented in Table 2. No patient required dialysis before surgery.

\section{Procedure Analysis}

The median ascending aorta diameter was $34 \mathrm{~mm}$ (range, $32-38 \mathrm{~mm}$ ) and the median graft proximal diameter was $40 \mathrm{~mm}$ (range, 38-46 mm).

An LSA bypass was performed in 30 patients and a transposition was performed in the other 8 patients. These procedures were performed during a first-step procedure before the endograft implantation in 33 patients. A transseptal wire was used in 1 patient to advance the endograft delivery system through very challenging arch anatomy. ${ }^{9}$

Reduced blood flow in the ascending aorta during endograft deployment was achieved either by rapid cardiac pacing $(n=35)$, inferior vena cava occlusion $(n=2)$, or pharmacologically induced cardiac arrest $(n=1)$.

One procedure required a sternotomy concomitant with femoral access. This patient had previously undergone an ascending aorta repair and a concomitant mechanical aortic valve replacement (noncompliance with inclusion criteria). It was thus not possible to advance the tip of the delivery system into the left ventricle through the mechanical valve. A conduit to the origin of the ascending graft was performed with the plan to exteriorize the tip of the delivery system. The endograft was implanted distal to the ideal position, making cannulation of the branches impossible. A chimney
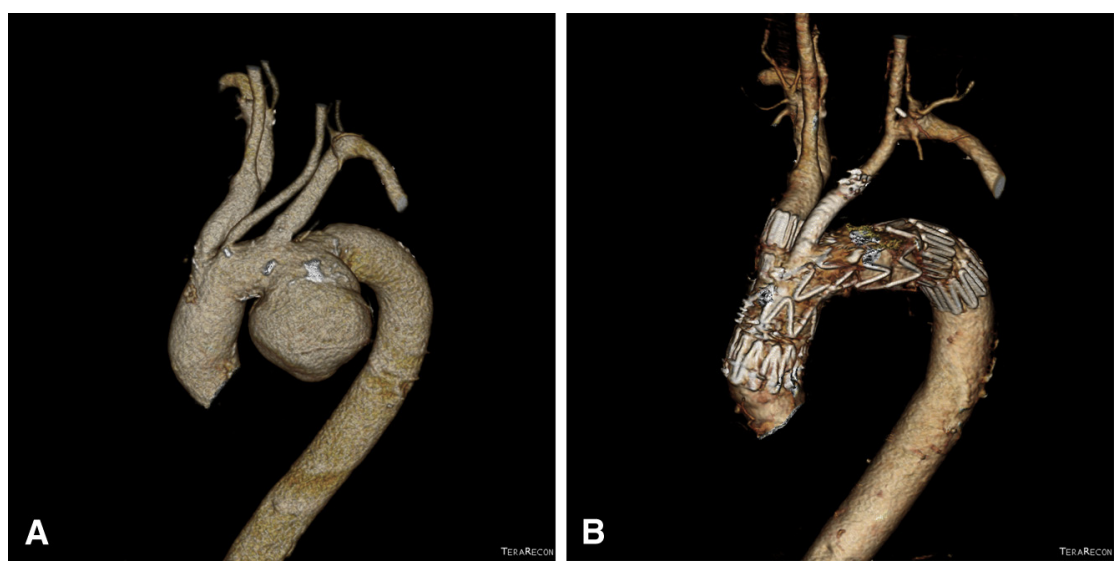

FIGURE 1. Three-dimensional volume rendering reconstruction computed tomography angiography of an arch aneurysm treated with an endograft with 2 internal side branches for the innominate trunk and the left common carotid. A, Preoperative. B, Postoperative. 


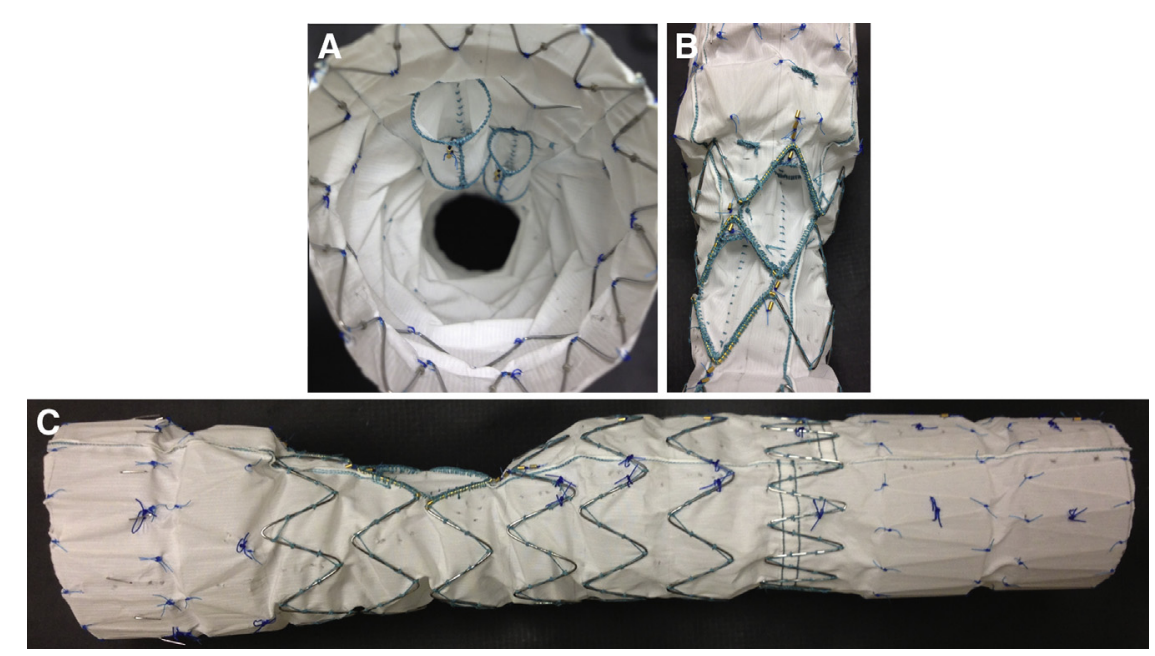

FIGURE 2. The arch endograft. A, Two internal side branches. B, An enlarged external opening at each distal end. C, The middle of the endograft is narrow to separate the opening of the side branches from the orifices of the supra-aortic trunks to facilitate catheterization and preserve blood flow to the supra-aortic trunks.

technique was thus performed to maintain perfusion of the supra-aortic vessels.

One patient required right axillofemoral bypass after device implantation because it was believed that a kink in the device due to tortuous ascending anatomy may have reduced the aortic cross-sectional luminal area, increasing afterload and decreasing systemic pressure. Three months later, this patient underwent sternotomy and conversion.

The median operative time was 250 minutes (range, 210.0-330.0 minutes). An access conduit was required in 13 patients; 8 were performed at the right axillary access, and 5 at the femoral access. The median fluoroscopy time was 45.7 minutes (range, 32.0-84.3 minutes) and the median volume of contrast media injected was $150 \mathrm{cc}$ (range, 95.0-207.5 cc). Perioperative complications

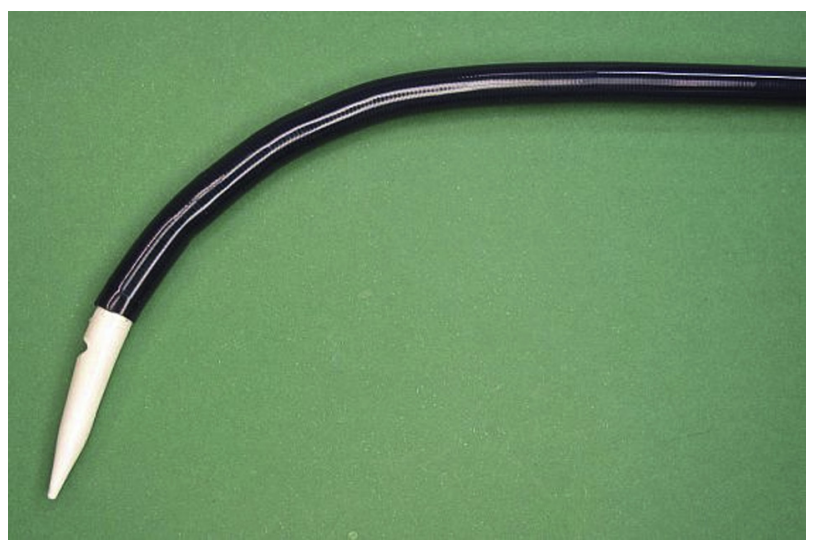

FIGURE 3. The delivery system in this device is curved and thus self-orienting in the arch, so no rotational movement is needed during implantation.
(Table 3) were observed in 7 patients $(18.4 \%$ [95\% CI, 5.0-30.9]).

\section{Early Follow-up}

The 30 -day mortality rate was $13.2 \%$. Median intensive care unit stay was 2 days (range, 1.5-4 days) and median hospital length of stay was 10 days (range, 7.5-15.5 days). Outcomes during early follow-up are reported in Table 4.

Technical success was obtained in 32 patients $(84.2 \%)$. Technical failures included 3 deaths occurring within the first 24 hours following surgery, 1 proximal type 1 endoleak diagnosed on completion angiogram, 1 failure to catheterize the innominate branch (necessitating an intraoperative right femoral to right carotid bypass), and 1 conversion to a chimney technique.

Endoleaks were diagnosed on the discharge postoperative CTA scan in 11 patients $(28.8 \%$ ), including 5 proximal type- 1 endoleaks, 3 type- 2 endoleaks, 1 type- 3 endoleak, and 2 endoleaks of undetermined origin. Among the type- 2 endoleaks, 1 originated from the innominate artery (catheterization failure described above), 1 from a bronchial artery, and 1 from the LSA.

Early secondary procedures were performed in 4 patients $(10.5 \%)$. Namely, balloon angioplasty of a type- 3 endoleak at the origin of an LCC branch 7 days after the initial procedure in 1 patient, plug insertion at the origin of the innominate artery to seal a type- 2 endoleak 30 days after the initial procedure in another patient, and 2 procedures related to an access site complication (1 axillary and the only sternotomy).

In addition to the complications responsible for early mortality, systemic complications were noted in 17 patients $(44.7 \%)$. Cerebrovascular complications were diagnosed in 6 patients $(15.8 \%)$, including 4 transient 
TABLE 2. Patient characteristics

\begin{tabular}{|c|c|c|c|c|}
\hline Characteristic & All cohort $(n=38)$ & Early experience group $(n=10)$ & Late experience group $(n=28)$ & $P$ value* \\
\hline Male gender & $27(71.1 ; 56.4-85.8)$ & $8(80.0 ; 53.9-100)$ & $19(67.9 ; 50.3-85.5)$ & .47 \\
\hline Age & $71(64-740)$ & $74.5(66-80.25)$ & $70(63-73)$ & .23 \\
\hline High blood pressure & $34(89.5 ; 79.7-99.3)$ & $9(90.0 ; 70.4-100)$ & $25(89.3 ; 77.5-100)$ & .95 \\
\hline Dyslipidemia & $25(65.8 ; 50.5-81.1)$ & $8(80.0 ; 53.9-100)$ & $17(60.7 ; 42.3-79.1)$ & .27 \\
\hline Prior aortic surgery & $21(55 ; 39.2-71.4)$ & $2(20 ; 0.0-46.1)$ & $19(67.9 ; 50.3-85.5)$ & .009 \\
\hline Smoking & $20(52.6 ; 36.6-68.7)$ & $5(50.0 ; 17.3-82.7)$ & $15(53.6 ; 34.8-72.4)$ & .85 \\
\hline Coronary disease & $15(39.5 ; 23.8-55.2)$ & $6(60.0 ; 28.1-91.9)$ & $9(32.1 ; 14.5-49.7)$ & .12 \\
\hline Dysrhythmia & $14(36.8 ; 21.3-52.3)$ & $5(50.0 ; 17.3-82.7)$ & $9(32.1 ; 14.5-49.7)$ & .32 \\
\hline Chronic obstructive pulmonary disease & $12(31.6 ; 16.7-46.5)$ & $3(30.0 ; 0.0-60.0)$ & $9(32.1 ; 14.5-49.7)$ & .90 \\
\hline Prior ascending aortic surgery & $12(31.6 ; 16.7-46.5)$ & $0(0)$ & $12(42.9 ; 24.3-61.5)$ & .012 \\
\hline Diabetes mellitus & $11(28.8 ; 14.2-43.6)$ & $2(20.0 ; 0.0-46.1)$ & $9(32.1 ; 14.5-49.7)$ & .47 \\
\hline Coronary bypass or stent & $9(23.7 ; 10.0-37.4)$ & $4(40.0 ; 8.1-71.9)$ & $5(17.9 ; 3.4-32.4)$ & .16 \\
\hline Renal insufficiency & $8(21.1 ; 8.0-34.2)$ & $3(30.0 ; 0.0-60.0)$ & $5(17.9 ; 3.4-32.4)$ & .42 \\
\hline Prior cerebral event & $7(18.4 ; 5.0-30.9)$ & $3(30.0 ; 0.0-60.0)$ & $4(14.3 ; 1.2-27.4)$ & .27 \\
\hline Peripheral artery disease & $6(15.8 ; 4.0-27.6)$ & $2(20.0 ; 0.0-46.1)$ & $4(14.3 ; 1.2-27.4)$ & 67 \\
\hline Left ventricular ejection fraction $<40 \%$ & $5(13.2 ; 2.2-24.2)$ & $1(10.0 ; 0.0-19.6)$ & $4(14.3 ; 1.2-27.4)$ & .73 \\
\hline Heart valve disease & $4(10.5 ; 0.7-20.3)$ & $0(0)$ & $4(14.3 ; 1.2-27.4)$ & .21 \\
\hline Home oxygen & $3(7.9 ; 0.0-16.5)$ & $1(10.0 ; 0.0-19.6)$ & $2(7.1 ; 0.0-16.9)$ & .77 \\
\hline Aneurysm & $28(73.7 ; 59.0-87.8)$ & $10(100)$ & $18(64.3 ; 46.3-82.3)$ & .028 \\
\hline Chronic dissection & $10(26.3 ; 12.2-40.4)$ & $0(0)$ & $10(35.7 ; 17.7-53.7)$ & .028 \\
\hline
\end{tabular}

Values for age are given as median (quartile 1-quartile 3). Other values are given as n ( $\% ; 95 \%$ confidence interval). Boldface indicates $P$ values $<.05 . *$ Early experience group versus late experience group.

ischemic attacks, 1 stroke, and 1 subarachnoid hemorrhage; full long-term recovery occurred in all patients. One spinal cord ischemia with full early recovery was observed postoperatively. One patient presented with postoperative bilateral diaphragmatic paralysis requiring permanent ventilation and 230 days of hospitalization, including 150 days in an intensive care unit. One patient with previous home oxygen presented with a pneumothorax. The other pulmonary complications were a chylothorax, which required no supplementary treatment, and 2 pulmonary infections that resolved with medical treatment. Two myocardial infarctions and 1 case of postoperative aortic insufficiency were medically treated. Two patients presented with acute postoperative renal insufficiencies that required transient dialysis $(5.3 \%)$.

TABLE 3. Intraoperative complications

\begin{tabular}{lc}
\hline \multicolumn{1}{c}{ Event } & \multicolumn{1}{c}{ Result } \\
\hline Access complications & $2(5.3 ; 0.0-12.6)$ \\
$\quad$ Right subclavian conduit disruption and thrombosis \\
Systemic complication & $3(7.9 ; 0.0-16.5)$ \\
$\quad$ Cardiac arrest at induction & \\
Compressive pneumothorax & \\
Hemorrhagic shock & $2(5.3 ; 0.0-12.6)$ \\
Device-related complications & \\
$\quad$ Failure to catheterize the innominate trunk & \\
Coverage of supra-aortic trunk origin requiring & \\
$\quad$ conversion to a chimney technique & $7(18.4 ; 6.1-30.7)$ \\
Total
\end{tabular}

Values are given as $\mathrm{n}(\% ; 95 \%$ confidence interval).

\section{Follow-up}

The median follow-up was 12 months (range, 6-12 months). During follow-up, no aortic arch aneurysm related death was depicted. Causes of late deaths are detailed in Table 5 .

Secondary procedures during follow-up were performed in 3 patients $(9.1 \%)$. One conversion to open surgery was performed because the endograft presented a kink with functional coarctation responsible for congestive heart failure 3 months after the initial procedure. One patient required an endovascular procedure because the LCC branch was partially obstructed. A proximal type 1 endoleak was treated by coil embolization and gluing 5 months after the initial procedure.

At the 6-month follow-up CTA scan the other type 1 endoleaks appeared to have spontaneously resolved. However the 2 type- 2 endoleaks seen on postoperative CTA scan were still observed; the early type 2 endoleak treated by plug insertion had sealed. None of the patients with a type 2 endoleak experienced sac enlargement. Both indeterminate-type endoleaks diagnosed at discharge had sealed when observed during follow-up CTA scans. Late major complications were not aneurysm related (Table 5).

\section{Comparative Analyses}

We compared the first 10 patients (the EE group) with the subsequent 28 patients (LE group). The groups were comparable when considering medical history and ASA score (Table 2). Intraoperative complications and secondary 
TABLE 4. Early follow-up

\begin{tabular}{lc}
\hline \multicolumn{1}{c}{ Event } & Result \\
\hline Early mortality & $5(13.2 ; 2.2-24.2)$ \\
Cause & \\
Cardiac arrest at induction & Day 1 \\
Hemorrhagic shock & Day 1 \\
Myocardial infarction & Day 1 \\
Undetermined etiology & Day 9 \\
Pulmonary infection & Day 30 \\
Procedure-related complications & $2(5.3 ; 0.0-12.6)$ \\
Infraclavicular seroma & $1(2.6 ; 0.0-7.7)$ \\
Innominate artery thrombosis & $1(2.6 ; 0.0-7.7)$ \\
Endoleak on postoperative computed & $11(28.9 ; 14.2-43.6)$ \\
tomography scan & \\
Type 1 & $5(13.2 ; 2.2-24.2)$ \\
Type 2 & $3(7.9 ; 0.0-16.5)$ \\
Type 3 & $1(2.6 ; 0.0-7.7)$ \\
Unknown & $2(5.3 ; 0.0-12.6)$ \\
Secondary procedures & $4(10.5 ; 0.7-20.3)$ \\
Endoleaks & $2(5.3 ; 0.0-12.6)$ \\
Access site & $2(5.3 ; 0.0-12.6)$ \\
Systemic complications & $17(44.7 ; 28.8-60.6)$ \\
Cerebrovascular & $6(15.8 ; 4.0-27.6)$ \\
Transient ischemic accident & $4(10.5 ; 0.7-20.3)$ \\
Stroke & $1(2.6 ; 0.0-7.7)$ \\
Meningeal hemorrhage & $1(2.6 ; 0.0-7.7)$ \\
Pulmonary & $5(13.2 ; 2.2-24.2)$ \\
Cardiac & $3(7.9 ; 0.0-16.5)$ \\
Spinal cord ischemia & $1(2.6 ; 0.0-7.7)$ \\
Renal failure requiring transient dialysis & $2(5.3 ; 0.0-12.6)$ \\
\hline Val & \\
&
\end{tabular}

Values are given as $\mathrm{n}(\% ; 95 \%$ confidence interval) or postoperative day.

procedures (Table 6) were higher in the EE group $(P=.04)$. Although not statistically significant, the early mortality and type 1 endoleak rates were higher in the EE group.

TABLE 5. Follow-up data for 33 survivors (median, 12 months [range, 6-12 months])

\begin{tabular}{lc}
\hline \multicolumn{1}{c}{ Event } & \multicolumn{1}{c}{ Result } \\
\hline Late mortality & $4(12.1 ; 0.7-23.5)$ \\
Pneumopathy & 62 \\
Septicemia & 90 \\
Ruptured abdominal aortic aneurysm & 150 \\
Hemorrhagic stroke & 229 \\
Endoleak & $3(9.1 ; 0.0-19.1)$ \\
Type 2 & $2(6.1 ; 0.0-14.3)$ \\
Type 1 & $1(3.0 ; 0.0-8.9)$ \\
Secondary procedures & $3(9.1 ; 0.0-19.1)$ \\
Type 1 endoleak & $1(3.0 ; 0.0-8.9)$ \\
Partial branch obstruction & $1(3.0 ; 0.0-8.9)$ \\
Open conversion & $1(3.0 ; 0.0-8.9)$ \\
Systemic complications & $4(12.1 ; 0.7-23.5)$ \\
Cerebrovascular & \\
Stroke & $1(3.0 ; 0.0-8.9)$ \\
Pituitary apoplexy & $1(3.0 ; 0.0-8.9)$ \\
Cardiac heart failure & $2(6.1 ; 0.0-14.3)$ \\
\hline Values are given as n $(\% ; 95 \%$ confidence interval) or postoperative day.
\end{tabular}

The median operative time and the median radiograph time were significantly increased in the EE group.

The influence of EE, ascending aortic diameter, and prior ascending aortic surgery on combined early mortality, stroke, and transient ischemic attack (ie, MAE) was evaluated (Table 7). MAEs were observed significantly more frequently in patients enrolled in the EE group $(P=.019)$ and if the proximal sealing zone diameter was $\geq 38 \mathrm{~mm}$ $(P=.026)$. Prior ascending aortic surgery had no significant influence on MAEs.

\section{DISCUSSION}

Here we describe our experience with a total endovascular approach to treat patients with arch aortic aneurysms and severe comorbidities considered at high risk for open and hybrid procedures. Technical success was achieved in 32 patients $(84.2 \%)$. Early cerebrovascular complications were diagnosed in 6 patients $(15.8 \%)$. When interpreting the analysis of early compared with later procedures, we infer that a learning curve for device design, patient selection, and device implantation does effect outcome; we found a trend toward improved outcomes in intraoperative complications, early mortality, and transient ischemic attack. We believe the results from this first series of patients undergoing endovascular arch branched graft repair show, in concept, that a pure endovascular approach to the arch may be possible for selected patients with current device technology after an important learning curve has elapsed.

Currently available endovascular options for arch repair include fenestrated endografts, ${ }^{11,12}$ in situ graft fenestration, ${ }^{13-15}$ and chimney techniques ${ }^{16,17}$ but open surgery is currently the gold standard for arch aneurysm repair. The literature reports mortality rates ranging from $2 \%$ to $16.5 \%$ and stroke rates ranging from $2 \%$ to $18 \%{ }^{1,2}$ However, these reports are heterogeneous because arch aneurysm repair can include many different techniques and can be associated with multiple different concurrent procedures to treat ascending or coronary pathology. ${ }^{18-26}$

The development of the total endovascular repair of arch aneurysms builds on the experience of endovascular repair of thoracoabdominal aortic aneurysm using customdesigned fenestrated and branched endografts. ${ }^{4-6}$ The technique and devices used today are evolving and minimal long-term data are available to inform the durability of the repair. ${ }^{27}$ Similarly, the endovascular approach to arch pathology has been reserved for patients deemed unfit for open and/or hybrid repair with no conventional options. The $7.1 \%$ mortality rate in this subset of patients reported in the LE group compares well with the open surgery series. The specific challenges of the arch endovascular repair are related to the potential for neurologic complications, the inherent arterial angulation, the high blood 
TABLE 6. Comparative analyses between first 10 patients (early experience group) and next 28 patients (late experience group)

\begin{tabular}{|c|c|c|c|}
\hline & Early experience $(\mathbf{n}=\mathbf{1 0})$ & Late experience $(n=28)$ & $P$ value \\
\hline Early mortality & $3(30.0 ; 0.0-60.0)$ & $2(7.1 ; 0-16.9)$ & .066 \\
\hline Overall mortality & $3(30.0 ; 0.0-60.0)$ & $6(21.4 ; 5.9-36.9)$ & .67 \\
\hline Technical failure & $3(30.0 ; 0.0-60.0)$ & $3(10.7 ; 0.0-22.5)$ & .15 \\
\hline Type 1 endoleak & $3(30.0 ; 0.0-60.0)$ & $2(7.1 ; 0-16.9)$ & .066 \\
\hline Intraoperative complications & $4(40 ; 8.0-72.0)$ & $3(10.7 ; 0.0-22.5)$ & .04 \\
\hline All secondary procedures & $4(40 ; 8.0-72.0)$ & $3(10.7 ; 0.0-22.5)$ & .04 \\
\hline Early secondary procedures for endoleak & $2(20 ; 0.0-46.1)$ & $0(0)$ & .015 \\
\hline All secondary procedures for endoleak & $3(30.0 ; 0.0-60.0)$ & $0(0)$ & .014 \\
\hline Transient ischemic attack and strokes & $3(30.0 ; 0.0-60.0)$ & $3(10.7 ; 0.0-22.5)$ & .15 \\
\hline Transient ischemic attack & $3(30.0 ; 0.0-60.0)$ & $1(3.6 ; 0.0-10.6)$ & .019 \\
\hline Stroke & $0(0)$ & $2(7.1 ; 0-16.9)$ & .38 \\
\hline Operative time, $\min$ & $320(271.5-360)$ & $248.3(199.0-270.0)$ & .03 \\
\hline Radiograph duration, min & $120(52.8-264.5)$ & $39(30.0-59.4)$ & .007 \\
\hline Volume of contrast media injected, cc & $150(136.0-220.0)$ & $150(86.0-206.25)$ & .34 \\
\hline Ascending aorta diameter $>38 \mathrm{~mm}$ & $4(40 ; 8.0-72.0)$ & $7(25 ; 8.7-41.3)$ & .37 \\
\hline
\end{tabular}

Values for operative time, radiograph duration, and volume of contrast media injected are given as median (quartile 1-quartile 3). Other values are given as n (\%; $95 \%$ confidence interval). Boldface indicates $P$ values $<.05$.

flow and pulsatile movement of the aorta in this area, and the proximity of the aortic valve. Moreover, other factors may make an endovascular approach more difficult or preclude it. For example, emergencies, because it generally takes between 6 and 8 weeks to manufacture a custom-made endograft. Further, target vessels need to be of appropriate length and luminal diameter, and there may be common endovascular contraindications such as inadequacy of access vessels due to extreme stenosis, calcifications, or angulations. Thus, at the current time, there are many limitations to this technology that makes its widespread use a challenge.

The comparison of early and late experiences, and the statistically significant outcomes that were found, reflects the importance of the learning curve in implantation as well as patient selection. The development of this device has been unique in that a true international shared experience has been attempted, with many of the investigators present for observation during early cases at some sites, as well as a collaborative effort to refine the indications for the device across the 10 centers. The need for a stable, long, and straight proximal landing zone was appreciated early. MAEs (ie, combined early mortality, strokes, and transient ischemic attacks) were higher for patients with ascending aorta $\geq 38 \mathrm{~mm}$. Large ascending aortic diameters create a number of problems, including less accurate deployment. Furthermore, large ascending aortic diameters are likely a sign of an unhealthy, less stable sealing zone.

Late enrollment included patients with prior ascending aortic surgery. Although this provides a stable proximal landing zone, there are potential problems. Significant angulation in previous ascending interposition grafts is now appreciated to be a contraindication to endovascular arch branch repair because of the stiff angle imposed by a reinforced distal anastomotic line or kink in the graft itself, which is unlikely to change shape or diameter with the radial force of a stent alone. Moreover, this angulation reduced the cross-sectional area of 1 device, leading to increased afterload and eventual heart failure. This was the 1 conversion in this series.

The branch design, with large open internal side branches and larger exterior openings, maintains cerebral circulation during cannulation and stenting. Minimizing the need for manipulation of a device once delivered into position is paramount because of the potential for embolization. The delivery system in this device is self-orienting, so no rotational movement is needed.

One of the limitations of our study is the small population being studied, which makes it difficult to draw robust statistical conclusions. Also, the evolving understanding of the

TABLE 7. Risk factors for early mortality and neurologic events

\begin{tabular}{lcc}
\hline & $\begin{array}{c}\text { EE }(\mathbf{n}=\mathbf{1 0}) \\
\text { versus LE }(\mathbf{n}=\mathbf{2 8})\end{array}$ & $\begin{array}{c}\text { AAD } \geq \mathbf{3 8} \text { mm }(\mathbf{n}=\mathbf{1 1}) \\
\text { versus AAD }<\mathbf{3 8} \text { mm }(\mathbf{n}=\mathbf{2 7})\end{array}$ \\
\hline Early mortality and neurologic events $(\mathrm{n}=11)$ & $6(60.0 ; 28.1-91.9)$ vs & $6(54.5 ; 13.7-85.3)$ vs \\
& $5(17.9 ; 3.4-32.4)$ & $5(18.5 ; 3.6-33.4)$ \\
$P$ value & $\mathbf{. 0 1 9}$ PAAS $(\mathbf{n}=\mathbf{2 6})$
\end{tabular}

Values are given as n (\%; $95 \%$ confidence interval). Boldface indicates $P$ values $<.05 . E E$, Early experience (first 10 patients); $L E$, late experience (later 28 patients); $A A D$, ascending aorta diameter; $P A A S$, prior ascending aortic surgery. 
indications for use for this device makes the study population, with respect to access vessels and morphology of ascending aortic landing zone, systematically different over time.

\section{CONCLUSIONS}

Conventional surgical repair of aortic arch aneurysms using cardiopulmonary bypass and hypothermic circulatory arrest remains the gold standard, but still carries substantial rates of mortality and morbidity. At the present time, with careful patient selection and operator experience, early use of this device extends the benefits of arch repair to patients who may not have other conventional options. We will continue to collect data as experience with the device increases and more indications and contraindications to its use are understood.

\section{References}

1. Moon MC, Morales JP, Greenberg RK. The aortic arch and ascending aorta: are they within the endovascular realm? Semin Vasc Surg. 2007;20:97-107.

2. Iba Y, Minatoya K, Matsuda H, Sasaki H, Tanaka H, Kobayashi J, et al. Contemporary open aortic arch repair with selective cerebral perfusion in the era of endovascular aortic repair. J Thorac Cardiovasc Surg. 2013;145(Suppl): S72-7.

3. Benedetto U, Melina G, Angeloni E, Codispoti M, Sinatra R. Current results of open total arch replacement versus hybrid thoracic endovascular aortic repair for aortic arch aneurysm: a meta-analysis of comparative studies. J Thorac Cardiovasc Surg. 2013;145:305-6.

4. Chuter TA, Rapp JH, Hiramoto JS, Schneider DB, Howell B, Reilly LM. Endovascular treatment of thoracoabdominal aortic aneurysms. J Vasc Surg. 2008;47:6-16.

5. Greenberg RK, Lu Q, Roselli EE, Svensson LG, Moon MC, Hernandez AV, et al. Contemporary analysis of descending thoracic and thoracoabdominal aneurysm repair: a comparison of endovascular and open techniques. Circulation. 2008; 118:808-17.

6. Guillou M, Bianchini A, Sobocinski J, Maurel B, D'elia PV, Tyrrell M, et al. Endovascular treatment of thoracoabdominalaortic aneurysms. J Vasc Surg. 2012;56:65-73.

7. Lioupis C, Corriveau MM, MacKenzie KS, Obrand DI, Steinmetz OK, Abraham CZ. Treatment of aortic arch aneurysms with a modular transfemoral multibranched stent graft: initial experience. Eur J Vasc Endovasc Surg. 2012; 43:525-32.

8. Spear R, Kaladji A, Roeder R, Haulon S. Endovascular repair of a chronic arch dissecting aneurysm with a branched endograft. Ann Thorac Surg. 2013;96: e39-41.

9. Rheaume P, Perini P, Daligault M, Maurel B, Sobocinski J, Azzaoui R, et al. Total endovascular repair of an aortic arch aneurysm using an externalized transseptal guidewire technique. Ann Thorac Surg. 2012;93: 1710-3.

10. Fillinger MF, Greenberg RK, McKinsey JF, Chaikof EL, Society for Vascular Surgery Ad Hoc Committee on TEVAR Reporting Standards. Reporting standards for thoracic endovascular aortic repair (TEVAR). J Vasc Surg. 2010; 52:1022-33.

11. Azuma T, Yokoi Y, Yamazaki K. The next generation of fenestrated endografts: results of a clinical trial to support an expanded indication for aortic arch aneurysm treatment. Eur J Cardiothorac Surg. 2013;44: e156-63.

12. Yokoi Y, Azuma T, Yamazaki K. Advantage of a precurved fenestrated endograft for aortic arch disease: simplified arch aneurysm treatment in Japan 2010 and 2011. J Thorac Cardiovasc Surg. 2013;145(Suppl): S103-9.

13. Sonesson B, Resch T, Allers M, Malina M. Endovascular total aortic arch replacement by in situ stent graft fenestration technique. J Vasc Surg. 2009;49: 1589-91.

14. Murphy EH, Dimaio JM, Dean W, Jessen ME, Arko FR. Endovascular repair of acute traumatic thoracic aortic transection with laser-assisted in-situ fenestration of a stent-graft covering the left subclavian artery. J Endovasc Ther. 2009;16: 457-63.

15. Sonesson B, Resch T, Dias N, Malina M. New temporary internal introducer shunt for brain perfusion during total endovascular arch replacement with in situ fenestration technique. J Vasc Surg. 2012;56:1162-5.

16. Ohrlander T, Sonesson B, Ivancev K, Resch T, Dias N, Malina M. The chimney graft: a technique for preserving or rescuing aortic branch vessels in stent-graft sealing zones. J Endovasc Ther. 2008;15:427-32.

17. Moulakakis KG, Mylonas SN, Dalainas I, Sfyroeras GS, Markatis F, Kotsis T, et al. The chimney-graft technique for preserving supra-aortic branches: a review. Ann Cardiothorac Surg. 2013;2:339-46.

18. Griepp RB, Stinson EB, Hollingsworth JF, Buehler D. Prosthetic replacement of the aortic arch. J Thorac Cardiovasc Surg. 1975;70:1051-63.

19. Svensson LG, Crawford ES, Hess KR, Coselli JS, Raskin S, Shenaq SA, et al. Deep hypothermia with circulatory arrest. Determinants of stroke and early mortality in 656 patients. J Thorac Cardiovasc Surg. 1993;106: 19-28.

20. Estrera AL, Miller CC III, Lee TY, Shah P, Safi HJ. Ascending and transverse aortic arch repair: the impact of retrograde cerebral perfusion. Circulation. 2008;118(Suppl):S160-6.

21. Svensson LG, Blackstone EH, Rajeswaran J, Sabik JF III, Lytle BW, Gonzalez-Stawinski G, et al. Does the arterial cannulation site for circulatory arrest influence stroke risk? Ann Thorac Surg. 2004;78:1274-84.

22. Patel HJ, Deeb GM. Ascending and arch aorta: pathology, natural history, and treatment. Circulation. 2008;118:188-95.

23. Di Eusanio M, Schepens MA, Morshuis WJ, Dossche KM, Kazui T, Ohkura K, et al. Separate grafts or en bloc anastomosis for arch vessels reimplantation to the aortic arch. Ann Thorac Surg. 2004;77:2021-8.

24. Immer FF, Moser B, Krahenbuhl ES, Englberger L, Stalder M, Eckstein FS, et al. Arterial access through the right subclavian artery in surgery of the aortic arch improves neurologic outcome and mid-term quality of life. Ann Thorac Surg. 2008;85:1614-8.

25. Olsson C, Eriksson N, Stahle E, Thelin S. The Swedish Heart Surgery Register: data quality for proximal thoracic aortic operations. Scand Cardiovasc J. 2006; 40:348-53

26. Sasaki H, Ogino H, Matsuda H, Minatoya K, Ando M, Kitamura S. Integrated total arch replacement using selective cerebral perfusion: a 6-year experience. Ann Thorac Surg. 2007;83(Suppl):S805-10.

27. Mastracci TM, Greenberg RK, Eagleton MJ, Hernandez AV. Durability of branches in branched and fenestrated endografts. J Vasc Surg. 2013;57: 926-33. 